\title{
Validity of the shuttle walk test as a functional assessment of walking ability in individuals with polyneuropathy
}

Citation for published version (APA):

Erdmann, P. G., Teunissen, L. L., van den Berg, L. H., Notermans, N. C., Schroeder, C. D., Bongers, B. C., \& van Meeteren, N. L. U. (2017). Validity of the shuttle walk test as a functional assessment of walking ability in individuals with polyneuropathy. Disability and Rehabilitation, 39(20), 2112-2118. https://doi.org/10.1080/09638288.2016.1217083

Document status and date:

Published: 01/01/2017

DOI:

10.1080/09638288.2016.1217083

Document Version:

Publisher's PDF, also known as Version of record

Document license:

Taverne

Please check the document version of this publication:

- A submitted manuscript is the version of the article upon submission and before peer-review. There can be important differences between the submitted version and the official published version of record.

People interested in the research are advised to contact the author for the final version of the publication, or visit the DOI to the publisher's website.

- The final author version and the galley proof are versions of the publication after peer review.

- The final published version features the final layout of the paper including the volume, issue and page numbers.

Link to publication

\footnotetext{
General rights rights.

- You may freely distribute the URL identifying the publication in the public portal. please follow below link for the End User Agreement:

www.umlib.nl/taverne-license

Take down policy

If you believe that this document breaches copyright please contact us at:

repository@maastrichtuniversity.nl

providing details and we will investigate your claim.
}

Copyright and moral rights for the publications made accessible in the public portal are retained by the authors and/or other copyright owners and it is a condition of accessing publications that users recognise and abide by the legal requirements associated with these

- Users may download and print one copy of any publication from the public portal for the purpose of private study or research.

- You may not further distribute the material or use it for any profit-making activity or commercial gain

If the publication is distributed under the terms of Article $25 \mathrm{fa}$ of the Dutch Copyright Act, indicated by the "Taverne" license above, 


\section{Validity of the shuttle walk test as a functional assessment of walking ability in individuals with polyneuropathy}

\section{Peter G. Erdmann, Laurien L. Teunissen, Leonard H. van den Berg, Nicolette} C. Notermans, Carin D. Schröder, Bart C. Bongers \& Nico L.U. van Meeteren

To cite this article: Peter G. Erdmann, Laurien L. Teunissen, Leonard H. van den Berg, Nicolette C. Notermans, Carin D. Schröder, Bart C. Bongers \& Nico L.U. van Meeteren (2017) Validity of the shuttle walk test as a functional assessment of walking ability in individuals with polyneuropathy, Disability and Rehabilitation, 39:20, 2112-2118, DOI: 10.1080/09638288.2016.1217083

To link to this article: https://doi.org/10.1080/09638288.2016.1217083

Published online: 06 Sep 2016.

Џll Article views: 167

View Crossmark data ¿
Submit your article to this journal $\square$ 


\title{
Validity of the shuttle walk test as a functional assessment of walking ability in individuals with polyneuropathy
}

\author{
Peter G. Erdmann ${ }^{a}$, Laurien L. Teunissen ${ }^{b}$, Leonard H. van den Berg ${ }^{c}$, Nicolette C. Notermans ${ }^{c}$, Carin D. Schröder ${ }^{d}$, \\ Bart C. Bongers ${ }^{\mathrm{e}}$ and Nico L.U. van Meeteren ${ }^{\mathrm{e}, \mathrm{f}}$ \\ ${ }^{a}$ Department School of Health, Avans University of Applied Sciences, Breda, the Netherlands; ${ }^{b}$ Department of Neurology and Clinical \\ Neurophysiology, St Antonius Hospital, Nieuwegein, the Netherlands; 'Department of Neurology and Neurosurgery, Rudolf Magnus Institute of \\ Neuroscience, University Medical Center Utrecht, Utrecht, the Netherlands; ${ }^{d}$ University Medical Center Utrecht and De Hoogstraat Rehabilitation,

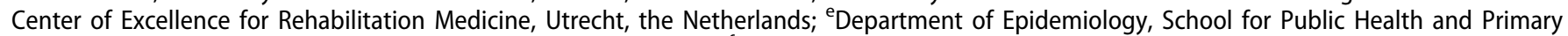

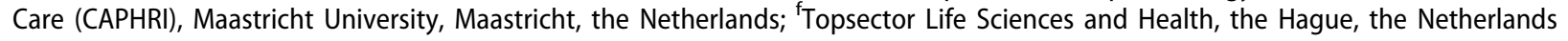

\begin{abstract}
Purpose: This study assessed the validity of the shuttle walk test (SWT) to evaluate walking ability in patients with polyneuropathy.

Methods: Forty-one patients with chronic idiopathic axonal polyneuropathy (CIAP) and 49 patients with multifocal motor neuropathy (MMN) performed both the 10-meter walk test (10MWT) and the SWT. Face validity was assessed by evaluating whether patients considered both tests to reflect their walking ability (Likert scale: $1=$ not at all, $10=$ very well). Concurrent validity was determined by Spearman rank-correlation analyses performed on the outcomes of both tests.

Results: Mean (SD) scores for how well the 10MWT and SWT reflected daily walking ability were $6.8(1.3)$ and $7.4(1.6)(p=0.117)$ in patients with CIAP and $6.9(1.2)$ and $7.9(1.0)(p=0.001)$ in patients with MMN, respectively. Correlation scores between both tests ranged from -0.70 to -0.82 , except for 18 patients with MMN with a "normal" walking speed at the 10MWT $(-0.21)$.

Conclusion: The SWT seems a valid instrument for assessing walking ability in individuals with CIAP and MMN. Moreover, the SWT seems to be useful for investigating the symptoms elicited by walking long distances and may be more sensitive to changes when compared to the 10MWT.

\section{> IMPLICATIONS FOR REHABILITATION}

- Patients with polyneuropathy mainly experience problems when walking long distances.

- The 10-meter walk test does not possess sufficient psychometrics to diagnose walking abilities in these circumstances.

- The shuttle walk test is a valid instrument for assessing walking ability in individuals with polyneuropathy and might be the preferred instrument of choice when compared to the 10-meter walk test.
\end{abstract}

\section{ARTICLE HISTORY}

Received 8 January 2016

Revised 12 July 2016

Accepted 21 July 2016

\section{KEYWORDS}

Performance-based test; functioning; walking ability; polyneuropathy; validity

\section{Introduction}

One of the major problems of individuals with polyneuropathy is their limited walking ability,[1-4] which is usually progressive. The generic 10-meter walk test (10MWT) [5,6] is frequently used [7-13] to measure walking ability, since there is no "true" gold standard method for assessing walking ability in a performance-based manner. Clinically, however, we often experience that individuals with polyneuropathy perform the 10MWT with ease and only experience problems when walking long distances. Consequently, the 10MWT often shows ceiling effects, $[2,9,10,13]$ implicating that the walking ability of individuals over short distances $(10 \mathrm{~m})$ is comparable to that of healthy adults.[14,15] Moreover, the responsiveness of the 10MWT in individuals with inflammatory polyneuropathy was shown to be poor.[9]

Hence, an extended walking test, such as the incremental shuttle walk test (SWT), may be more appropriate for assessing their walking ability.[2] The SWT was developed to measure the functional capacity, expressed in maximal walking distance, of individuals with chronic airway obstruction.[16] Nowadays, its clinimetric properties have been established in individuals with chronic heart failure and those with chronic respiratory diseases. $[17,18]$ Reference values for maximal walking distance on the SWT have been established for healthy individuals.[19,20] The validation of this test for measuring walking ability of patients with polyneuropathy requires assessment of both functional capacity and walking ability, to ensure that the patients' walking performance reflects limitations due to their neurological disease rather than, for example, impaired cardiopulmonary fitness. We have previously found the SWT to be feasible in individuals with chronic idiopathic axonal polyneuropathy (CIAP) and multifocal motor neuropathy (MMN).[3,21,22] CIAP is a slowly progressive distal symmetric sensory or sensorimotor polyneuropathy with axonal degeneration that mainly affects the legs. In these individuals, known causes of polyneuropathy have been excluded by extensive laboratory examination. The mean age at onset of CIAP is 57 years, with a male predominance.[10,23] MMN is a chronic immune-mediated neuropathy characterized by slowly 


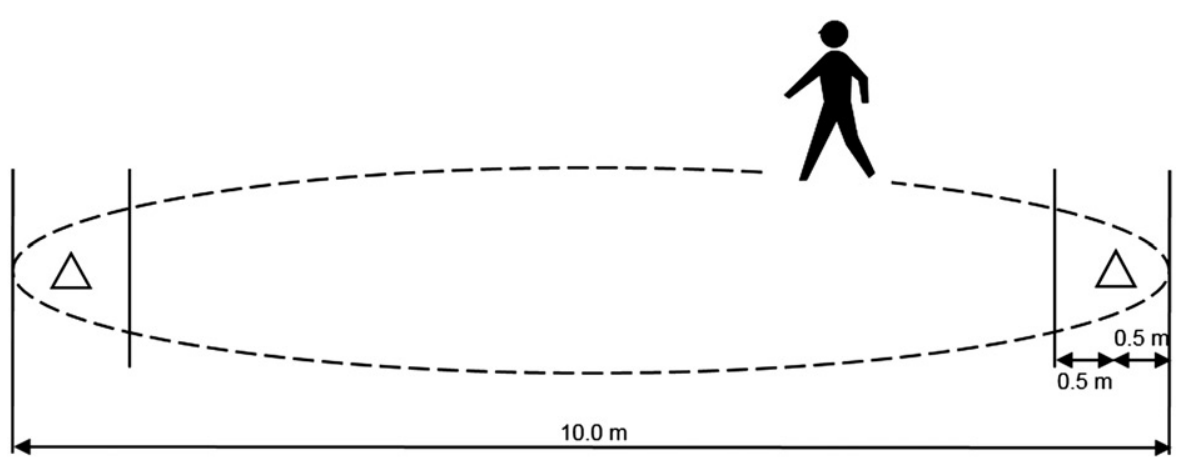

Figure 1. The shuttle walk test.

progressive, predominantly distal asymmetric limb weakness, in the arms more than the legs, not accompanied by sensory loss. The mean age at onset is 40 years, with a male predominance.[24] The aim of this cross-sectional study was to assess face validity and concurrent validity of the SWT for the evaluation of walking ability of patients with CIAP and patients with MMN.

\section{Methods}

\section{Participants}

Forty-one clinically stable patients diagnosed with CIAP and 49 clinically stable patients diagnosed with MMN who attended the outpatient clinic of the Department of Neuromuscular Diseases of the University Medical Center Utrecht between 2007 and 2009 for their annual checkup participated in this study. CIAP and MMN were chosen because our department is a referral center for patients with these disorders, many of whom participate in long-term, follow-up research. All participants gave informed consent. Data collection, analysis, and publication were approved by the ethics committee of the University Medical Center Utrecht.

\section{Study design}

The study had a cross-sectional design. The participants came to the gymnasium of the outpatient clinic, where demographic data, comorbidities, medication use, and the use of walking aids were recorded and they were classified into (dis)ability subgroups, using the 5-class modified Rankin scale.[25] To assess concurrent validity of the incremental SWT, the participants performed both the 10MWT and the incremental SWT. There was a five-minute interval between the tests to allow the participants to recover. Face validity of the incremental SWT was assessed by means of participant interviews after completion of the two walking tests. The participants were asked: "How well does the 10MWT and the SWT reflect your walking ability in daily life? Please score each test, with scores ranging from 1 (not at all) to 10 (very well)". All measurements were performed by a physical therapist (PGE) who has more than 10 years of clinical experience with these patient groups and with the various tests used.

\section{Measurements}

\section{0-Meter walk test}

For the 10MWT, all participants were asked to walk a 10-meter course from standing still, at their preferred walking speed, using a walking aid if needed.[5] The time needed to walk the distance was recorded using a stopwatch. They started walking after a countdown, and the physical therapist, for safety and support reasons, walked slightly behind the participant. The test and timing stopped immediately when a participant stepped onto or over the ten-meter line. We calculated the mean time scores of three assessments. Normative data for walking speed have been determined for healthy adults.[14,15]

\section{Incremental shuttle walk test}

When walking the incremental SWT, the participants were asked to walk around a 10-meter course marked by two cones placed nine meters apart, thus allowing half a meter for turning round at each end (Figure 1). Walking speed was regulated by prerecorded metronomic signals from a standard CD player. The participant was asked to walk around the cones at each signal. In the original version of the SWT, the initial walking speed of $1.8 \mathrm{~km} / \mathrm{h}(0.50 \mathrm{~m} /$ s) increases by $0.6 \mathrm{~km} / \mathrm{h}(0.17 \mathrm{~m} / \mathrm{s})$ every minute up to a maximum walking speed of $8.5 \mathrm{~km} / \mathrm{h}(2.37 \mathrm{~m} / \mathrm{s})$. We used a modified version of the SWT (see appendix) in which the initial walking speed of $3.0 \mathrm{~km} / \mathrm{h}(0.83 \mathrm{~m} / \mathrm{s})$ was increased by $0.5 \mathrm{~km} / \mathrm{h}(0.14 \mathrm{~m} / \mathrm{s})$ every two minutes up to a maximum walking speed of $7.0 \mathrm{~km} / \mathrm{h}$ $(1.94 \mathrm{~m} / \mathrm{s})$.[26] This modification was made in order to allow participants to adapt to walking at each speed and thus probably better mimics walking long distances in daily life. Standardized instructions were given prior to the test and participants were encouraged to walk as long as possible (maximal effort) without risking falling. The use of walking aids (including orthopedic shoes and ankle-foot orthoses) was permitted. Again, the physical therapist, for safety and support reasons, walked slightly behind the individual. The test was terminated by the physical therapist if the participant's foot was not on or within a line placed half a meter from the cone at the prerecorded signal for three consecutive shuttles. Moreover, the test was terminated whether the participant stopped walking for whatever reason, or when the participant completed the entire test (i.e., 150 times the 10-meter course). The number of shuttles (i.e., 10-meter courses) was the primary outcome measure of the SWT in which higher numbers are indicative of a better walking ability, with a maximum of $1500 \mathrm{~m}$ (see appendix). In addition, heart rate and perceived exertion (Borg scale) were measured before and immediately after the incremental SWT. The Borg scale [27] is a 11-point Likert scale for perceived exertion, with scores ranging from 0 ("nothing at all") to 10 ("very, very strong").

\section{Statistical analysis}

All data were expressed as mean \pm SD or median (range) and analyses were performed using the Statistical Package for the Social Sciences version 15.0 (SPSS Inc., Chicago, IL). Data were tested for normality using Kolmogorov-Smirnov tests. Face validity of the incremental SWT was assessed by evaluating whether patients 
considered the 10MWT and SWT to reflect their walking ability at a 10 -point Likert scale ( $1=$ not at all, $10=$ very well). Data on the symptoms experienced by the participants after completing the SWT were analyzed. Concurrent validity of the incremental SWT was assessed using Spearman's rank correlation analysis between the main outcome parameter of the 10MWT (mean time to complete the 10-meter distance) and the main outcome parameter of the incremental SWT (the number of completed shuttles). Moreover, both groups were categorized into individuals who had normative time scores on the 10MWT ("normal" walkers), and those who had higher than normative time scores on the 10MWT ("slow" walkers). Participants were assumed to be "normal" walkers whenever their time scores were within two standard deviations of the mean normative score [14] or within the $95 \%$ confidence interval.[15] In this way, it would be possible to assess the discriminative properties of the incremental SWT (group validity), as well as to detect differences in correlation coefficients between the two groups, and hence differences in the assessment of walking ability with the two tests. A priori, it was inferred that the SWT might be particularly clinically useful for assessing the walking ability of individuals who walk at normal speed on the 10MWT. Differences in correlation coefficients between the two groups were investigated with bootstrap analysis.[28] Walking ability might be influenced by sex, age, height, and the use of walking aids. Subanalysis by means of hierarchical multiple univariate linear regression analysis (enter procedure) was, therefore, carried out to investigate the contribution of each of these determinants. To this end, the outcome on the SWT was used as dependent variable and the outcome on the 10MWT, sex, age, height, and walking aids as independent variables. With help of the linear regression analysis, the relative importance of the independent variables is expressed as a statistically significant standardized beta coefficient. All tests were two-sided and $p$ values $<0.05$ were considered statistically significant.

\section{Results}

A total of 47 patients with CIAP and 49 patients with MMN were included in this study. Six participants with CIAP were excluded from the study, since they were unable to perform the SWT because of neuropathic pain in the lower legs or feet $(n=5)$ or impaired balance $(n=1)$. All excluded participants used walking aids. The mean (SD) 10MWT score of the excluded individuals was 24.9 (9.5) S, which was significantly higher than the 10MWT score of the participants in the CIAP study group who also performed the SWT $(9.7(2.5) s)(p<0.05)$. In the MMN group, all participants were able to perform the SWT.

Demographics, comorbidity, and the use of walking aids are presented in Table 1. About two-thirds of the participants were classified as Rankin 2, that is, "slight disability: unable to carry out all previous activities but able to look after own affairs without assistance". Five participants with CIAP (12\%) and one with MMN (2\%) had two or more comorbidities. Four participants with CIAP (10\%) and two with MMN (4\%) were taking beta-adrenergic blocking agents. Five participants with CIAP (12\%) and two with MMN (4\%) used a combination of orthopedic shoes/ankle-foot orthoses and walking aids.

Test results are presented in Table 2. One participant with CIAP and one participant with MMN were able to walk a maximum of $10 \mathrm{~m}$ (one shuttle) during the SWT. Six participants with CIAP (13\%) and six participants with MMN (12\%) completed all 150 shuttles on the SWT. Nine participants with CIAP (22\%) and 18 participants with MMN (37\%) scored $<8 \mathrm{~s}$ on the $10 \mathrm{MWT}$. Mean (SD) scores for how well the 10MWT and SWT reflected daily
Table 1. Participant characteristics.

\begin{tabular}{|c|c|c|}
\hline Demographics & CIAP $n=41$ & MMN $n=49$ \\
\hline Age $(y)$ & $66.2(9.6)$ & $51.5(11.1)$ \\
\hline $\operatorname{Sex}(m / f)$ & $30 / 11$ & $35 / 14$ \\
\hline Disease duration $(\mathrm{y})$ & $6.5(5.3)$ & $2.0(0.6)$ \\
\hline \multicolumn{3}{|l|}{ Modified Rankin Scale score } \\
\hline 0 & 0 & 1 \\
\hline 1 & 2 & 6 \\
\hline 2 & 33 & 32 \\
\hline 3 & 6 & 10 \\
\hline 4 & 0 & 0 \\
\hline \multicolumn{3}{|l|}{ Heart failure } \\
\hline Hypertension & 6 & 1 \\
\hline Arrhythmia & 3 & 0 \\
\hline Angina pectoris & 2 & 1 \\
\hline Valvular heart disease & 0 & 2 \\
\hline COPD & 3 & 3 \\
\hline Diabetic & 0 & 1 \\
\hline Ankylosing spondylitis & 0 & 1 \\
\hline Lumbar disc herniation & 5 & 1 \\
\hline Low back pain & 2 & 1 \\
\hline Total hip prothesis & 2 & 0 \\
\hline Cruciate ligament/meniscus & 1 & 2 \\
\hline Ankle fracture & 0 & 1 \\
\hline Cerebrovascular incident & 1 & 0 \\
\hline Depression & 3 & 0 \\
\hline \multicolumn{3}{|l|}{ Walking aids } \\
\hline Ankle-foot orthosis & 6 & 7 \\
\hline Orthopedic shoes & 5 & 3 \\
\hline Walking cane & 8 & 0 \\
\hline Crutch & 1 & 0 \\
\hline Rollator & 2 & 1 \\
\hline
\end{tabular}

CIAP: chronic idiopathic axonal polyneuropathy; MMN: multifocal motor neuropathy.

Values are expressed as means (SD) or as frequencies.

walking ability were $6.8(1.3)$ and $7.4(1.6)(p=0.117)$ in patients with CIAP and $6.9(1.2)$ and $7.9(1.0)(p=0.001)$ in patients with MMN, respectively. The distribution of walking test scores for each group, including linear line fit, are shown in Figures 2, 3, and 4.

\section{Face validity}

The Likert scores for how well the 10MWT and the SWT reflected daily walking ability are presented in Table 2. In general, the majority of the participants (58\% with CIAP and 59\% with MMN) considered the SWT to better reflect their daily walking ability than the 10MWT: these participants had mean (SD) time scores on the 10MWT of 8.9 (2.2) and 8.1 (1.3) s, respectively. Additionally, all these participants stated that the symptoms they experienced after completion of the SWT were similar to those experienced in daily life. This was not the case for the 10MWT. In contrast, 35\% of the participants with CIAP and $20 \%$ of the participants with MMN considered the 10MWT to better reflect their daily walking ability than the SWT; they had mean (SD) time scores on the 10MWT of 11.2 (2.4) and 9.4 (3.4) s, respectively. The remaining participants with CIAP and MMN considered both tests to reflect their walking ability equally.

Twenty-three (56\%) participants with CIAP and 24 (49\%) with MMN felt that their legs "blocked" after termination of the SWT, that is, they could not move their legs any faster, but did not experience this as a natural transition to running (Table 2). Another symptom was a sensation of fatigue in the legs, which was mentioned by six participants with CIAP (15\%) and by five participants with MMN (10\%). Only one participant (heart rate at the end of the SWT of 124 beats/min [73\% of the predicted maximal heart rate]) stopped the test because of perceived 
Table 2. 10MWT and SWT results.

\begin{tabular}{|c|c|c|}
\hline Test & CIAP $n=41$ & MMN $n=49$ \\
\hline \multicolumn{3}{|l|}{ 10MWT } \\
\hline Time score (sec) & $9.7(2.5)$ & $8.6(2.1)$ \\
\hline Representativeness of test ( $0-10$ points) & $6.8(1.3)$ & $6.9^{\mathrm{a}}(1.2)$ \\
\hline \multicolumn{3}{|l|}{ SWT } \\
\hline Shuttle score $(n)$ & $62.6(46.9)$ & $90.1(41.9)$ \\
\hline Representativeness of test ( $0-10$ points) & $7.4(1.6)$ & $7.9^{\mathrm{a}}(1.0)$ \\
\hline \multicolumn{3}{|l|}{ Reason for stopping $(n)$} \\
\hline Did not reach cone & 32 & 37 \\
\hline Test completed & 6 & 6 \\
\hline Patient stopped & 3 & 6 \\
\hline \multicolumn{3}{|l|}{ Symptoms when stopping $(n)$} \\
\hline Legs "blocked" & 23 & 24 \\
\hline Fatigue legs & 6 & 5 \\
\hline Balance/stumbling & 0 & 3 \\
\hline Painful legs & 4 & 0 \\
\hline Muscle strength impairment & 0 & 3 \\
\hline Legs cramps & 0 & 1 \\
\hline Normal transition to running & 1 & 6 \\
\hline Fall & 1 & 0 \\
\hline Exhaustion & 0 & 1 \\
\hline No complaints (i.e., test completed) & 6 & 6 \\
\hline Heart rate before SWT (beats/min) & $73.2(13.4)$ & $71.7(10.8)$ \\
\hline Heart rate after SWT (beats/min)/\%predicted & $\begin{array}{c}103.8 / 64 \% \\
(20.0) /(12 \%)\end{array}$ & $\begin{array}{c}111.9 / 65 \% \\
(18.7) /(10 \%)\end{array}$ \\
\hline Exertion before SWT (Borg score $0-10$ points) & $2(0-8)$ & $1(0-4)$ \\
\hline Exertion after SWT (Borg score 0-10 points) & $4(1-10)$ & $3(1-7)$ \\
\hline \multicolumn{3}{|c|}{$\begin{array}{l}\text { 10MWT: 10-meter walk test; SWT: shuttle walk test; CIAP: chronic idiopathic } \\
\text { axonal polyneuropathy; MMN: multifocal motor neuropathy } \\
\text { Values are expressed as means }(S D) \text { or as medians (range), unless stated } \\
\text { otherwise. } \\
\text { at Significant difference }(p=0.001) \text { between the scores for the 10MWT and SWT }\end{array}$} \\
\hline
\end{tabular}

exhaustion (Table 2). The six participants in each group who were able to complete the SWT did not report walking disability in daily life.

\section{Concurrent validity}

Table 3 shows the correlation coefficients between 10MWT scores and SWT scores for the "normal" walkers and the "slow" walkers (see statistical analysis). The correlation coefficients were high for all participants with CIAP (Spearman's $r$ values ranging from -0.82 to -0.83 ) and for "slow" walkers with MMN (Spearman's $r$ value $-0.70)$. This means that participants who walked faster on the 10MWT walked further (more shuttles) on the SWT. The correlation was low (Spearman's $r$ value -0.21 ) for the participants with MMN who walked at "normal" (i.e., normative) speed.

Hierarchical multiple univariate linear regression analysis showed that the 10MWT and age had significant beta values of -0.66 and -0.20 in the CIAP group, and -0.53 and -0.33 in the MMN group. The beta values for sex, body height, disease duration, and the use of walking aids were less than 0.10 . Therefore, only 10MWT score and age contributed significantly to the explained variance in SWT score.

\section{Discussion}

To our knowledge, this is the first detailed study to assess the validity of the SWT in evaluating walking ability in individuals with polyneuropathy. Walking ability was successfully assessed with the SWT, without apparent large floor and ceiling effects. Moreover, the SWT demonstrated that most participants with CIAP and MMN had walking disability and related symptoms. These problems were not expected in participants with $M M N$, because these

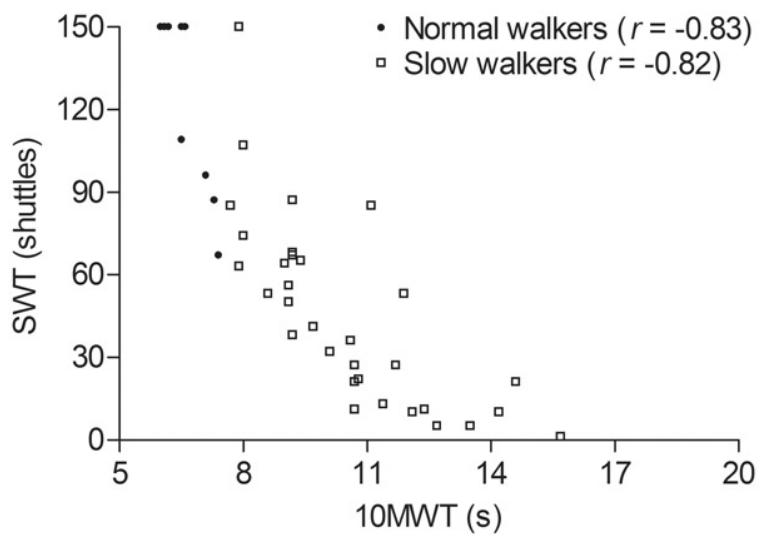

Figure 2. Relation between the 10MWT and the SWT in participants with CIAP $(n=41) .10 \mathrm{MWT}=10$-meter walk test, SWT $=$ shuttle walk test, $\bullet=$ participants walking at a normative speed during the 10MWT, $\square=$ participants walking slower than the normative speed during the 10MWT, $r=$ Spearman's $r$.

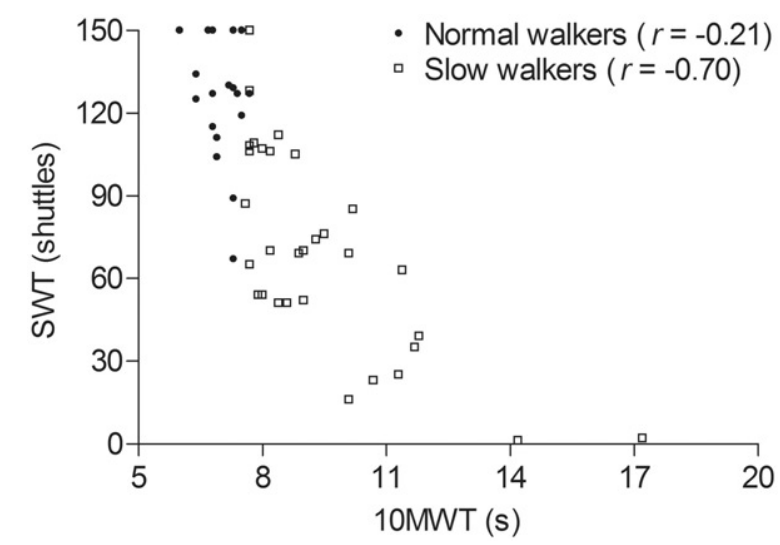

Figure 3. Relation between the 10MWT and the SWT in participants with MMN ( $n=49$ ). $10 \mathrm{MWT}=10$-meter walk test, $\mathrm{SWT}=$ shuttle walk test, $\bullet=$ participants walking at a normative speed during the 10MWT, $\square=$ participants walking slower than the normative speed at the 10MWT, $r=$ Spearman's $r$.

patients typically have major problems with dexterity, not walking ability.[2] Overall, SWT scores correlated well with 10MWT scores. The participants considered the SWT to best reflect their daily walking ability, and the symptoms they experienced after performing the SWT mimicked those experienced in daily life. Thus the SWT would appear to be a clinically useful instrument for assessing walking ability in individuals with polyneuropathy.

Up till now, questionnaires have been designed to assess the walking ability of individuals with polyneuropathy.[4] However, the participants' rating of their performance may differ quite a bit from their actual performance.[3,29] Therefore, performance-based instruments such as the 10MWT and, based on this study, especially the SWT can be used to measure the walking ability of patients with polyneuropathy. An alternative performance-based test might be the 6-min walk test. This test was originally developed to assess functional capacity and has been used to assess the walking ability of individuals with diabetic neuropathy.[30] We chose the SWT because the patients encountered walking disability after walking long distances. The 6-min walk test lasts only six minutes, whereas the SWT may last up to $18 \mathrm{~min}$. Therefore, it is more likely that patients encounter their problems walking long distances at the SWT.

In this study, we did not examine in detail the nature of the symptoms as experienced by the participants after the SWT. 


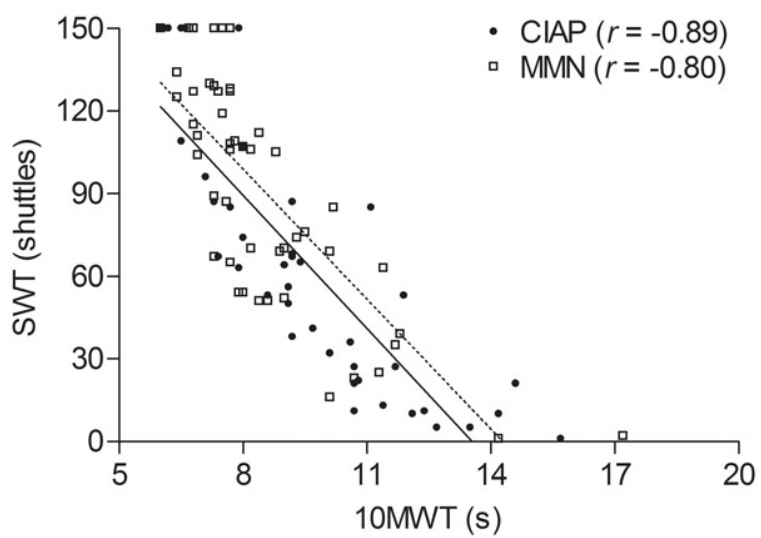

Figure 4. Relation between the 10MWT and the SWT in participants with CIAP $(n=41)$ and MMN $(n=49)$. 10MWT= 10-meter walk test, SWT = shuttle walk test, $\mathrm{CIAP}=$ chronic idiopathic axonal polyneuropathy, $\mathrm{MMN}=$ multifocal motor neuropathy, $\bullet=$ CIAP (solid regression line), $\square=$ MMN (dotted regression line), $r=$ Spearman's $r$

Table 3. Spearman correlation coefficients between 10MWT and SWT.

\begin{tabular}{llll}
\hline & & \multicolumn{2}{c}{$\begin{array}{c}\text { Walking performance } \\
\text { on the 10MWT }\end{array}$} \\
\cline { 3 - 4 } & Group & Normal & Slow \\
\hline Walking performance & $\operatorname{CIAP}(n=41)$ & -0.83 & -0.82 \\
on the SWT & $\mathrm{MMN}(n=49)$ & -0.21 & -0.70 \\
& Total $(n=90)$ & -0.46 & -0.80 \\
\hline
\end{tabular}

10MWT: 10-meter walk test; SWT: shuttle walk test; CIAP: chronic idiopathic axonal polyneuropathy; MMN: multifocal motor neuropathy

Normal walkers, persons who walked at a normative speed during the 10MWT.

Slow walkers, persons who walked slower than the normative speed during the 10MWT.

"Blocking legs", which was frequently mentioned by the participants, may have been caused by their neural pathology, but may also have been caused by an impaired oxidative capacity of the muscles due to deconditioning, medication use, aging, or poor nutritional status, as has been described in patients with lung transplantation.[31] Additional research is warranted to investigate the association between participants' symptoms during the SWT and their neuropathology. Post hoc analysis showed that only three participants with CIAP and four participants with MMN had a heart rate at the end of the SWT $>80 \%$ of their predicted maximal heart rate [32], meaning that most participants in this study did not exerted themselves maximally during the SWT and that the SWT was a symptom-limited test. Only one patient stopped the SWT due to exhaustion, and mean post-test Borg scale scores for perceived exertion were low. We did not encourage the patients during the SWT. Encouragement is frequently used in the assessment of functional exercise capacity, and the assessment of functional exercise capacity was not the aim of this study.

Compared to the 10MWT time scores, the SWT time scores of the 27 "normal" walkers showed substantial variation in both groups (a range of $1.5 \mathrm{~s}$ on the 10MWT and a range of nearly $60 \mathrm{~s}$ on the SWT) (Figure 3). Thus, the SWT may be more sensitive to changes and therefore might serve as a test to evaluate therapy or to collect longitudinal data in individual patients in order to measure disease progression. This, however, needs to be confirmed in a properly performed sensitivity-to-change study.[33] It was not possible to measure the SWT performance of very slow walking subjects who took longer than $12 \mathrm{~s}$ to complete the 10MWT; when walking the SWT they did not reach the first cone in time. Future studies should investigate whether a starting walking speed on the SWT of $2.0 \mathrm{~km} / \mathrm{h}$ or $2.5 \mathrm{~km} / \mathrm{h}$ is more appropriate for these patients.

A limitation of this study is the absence of a true gold standard for assessing walking ability over long distances. Secondly, 12 participants were able to walk all 150 shuttles on the SWT. An extended SWT with higher walking speed might have avoided this ceiling effect. Bear in mind that with higher walking speeds participants might need to run. Finally, we did not measure oxygen saturation in our participants and the heart rate assessment was performed manually.

This study showed that the SWT is useful for measuring walking ability in individuals with CIAP and MMN, especially in those whose time scores on the 10MWT are the same as healthy controls (i.e., time scores $<9 \mathrm{~s}$ on the 10MWT), since the 10MWT does not possess sufficient discriminative power in these individuals. Moreover, the SWT seems to be useful for investigating the symptoms elicited by walking long distances. The 10MWT may be helpful to assess walking ability during short walks, and when time scores $>9 \mathrm{~s}$ are expected. The SWT may serve as a performance-based diagnostic test and help to guide tailoring of immunological and rehabilitation interventions.[34] The SWT may also be useful in other polyneuropathies and may be complementary to validated tests recommended by the European Inflammatory Neuropathy Cause and Treatment Group (INCAT) study group.[35] Future studies should assess the reliability and responsiveness of the SWT and establish disease-specific reference values for patients with polyneuropathies and healthy males and females of different ages.

\section{Conclusion}

In this study, we established the face validity and concurrent validity of the SWT for assessing walking ability of individuals with CIAP and MMN. Moreover, the SWT seems to be useful for investigating the symptoms elicited by walking long distances, and may be more sensitive to changes when compared to the 10MWT. Therefore, it might be the preferred instrument of choice when compared to the 10MWT.

\section{Disclosure statement}

The authors report no conflicts of interest. The authors alone are responsible for the content and writing of the manuscript.

\section{Funding}

This research received no specific grant from any funding agency in the public, commercial, or not-for-profit sectors.

\section{References}

[1] Lindeman E, Leffers P, Spaans F, et al. Strength training in patients with myotonic dystrophy and hereditary motor and sensory neuropathy: a randomized clinical trial. Arch Phys Med Rehabil. 1995;76:612-620.

[2] Erdmann PG, van Meeteren NLU, Kalmijn $S$, et al. Functional health status of patients with chronic inflammatory neuropathies. J Peripher Nerv Syst. 2005;10:181-189.

[3] Graham RC, Hughes RA. Clinimetric properties of a walking scale in peripheral neuropathy. J Neurol Neurosurg Psychiatry. 2006;77:977-979.

[4] Schröder C, Johnston M, Teunissen L, et al. Perceived control is a concurrent predictor of activity limitations in 
patients with chronic idiopathic axonal polyneuropathy. Arch Phys Med Rehabil. 2007;88:63-69.

[5] Wade DT. Measurements in neurological rehabilitation. Oxford: Oxford University Press; 1992.

[6] Rossier P, Wade DT. Validity and reliability comparison of 4 mobility measures in patients presenting with neurologic impairment. Arch Phys Med Rehabil. 2001;82:9-13.

[7] Hughes R, Bensa S, Willison $\mathrm{H}$, et al. Randomized controlled trial of intravenous immunoglobulin versus oral prednisolone in chronic inflammatory demyelinating polyradiculoneuropathy. Ann Neurol. 2001;50:195-201.

[8] Comi G, Roveri L, Swan A, et al. A randomised controlled trial of intravenous immunoglobulin in $\lg \mathrm{M}$ paraprotein associated demyelinating neuropathy. J Neurol. 2002;249:1370-1377.

[9] Merkies IS, Schmitz PI, Van Der Meché FG, et al. Comparison between impairment and disability scales in immune-mediated polyneuropathies. Muscle Nerve. 2003;28:93-100.

[10] Hughes RA, Umapathi T, Gray IA, et al. A controlled investigation of the cause of chronic idiopathic axonal polyneuropathy. Brain. 2004;127:1723-1730.

[11] Reilly MM, de Jonghe P, Pareyson D. 136th ENMC international workshop: Charcot-Marie-tooth disease type $1 \mathrm{~A}$ (CMT1A) 8-10 April 2005, Naarden, the Netherlands. Neuromuscul Disord. 2006;16:396-402.

[12] Solari A, Laurà M, Salsano E, et al. Reliability of clinical outcome measures in Charcot-Marie-Tooth disease. Neuromuscul Disord. 2008;18:19-26.

[13] Dalakas MC, Rakocevic G, Salajegheh M, et al. Placebo-controlled trial of rituximab in IgM anti-myelin-associated glycoprotein antibody demyelinating neuropathy. Ann Neurol. 2009;65:286-293.

[14] Bohannon RW. Comfortable and maximum walking speed of adults aged 20-79 years: reference values and determinants. Age Ageing. 1997;26:15-19.

[15] Steffen TM, Hacker TA, Mollinger L. Age- and genderrelated test performance in community-dwelling elderly people: six-minute walk test, Berg balance scale, timed up \& go test, and gait speeds. Phys Ther. 2002;82:128-137.

[16] Singh SJ, Morgan MD, Scott S, et al. Development of a shuttle walking test of disability in patients with chronic airways obstruction. Thorax. 1992;47:1019-1024.

[17] Solway S, Brooks D, Lacasse Y, et al. A qualitative systematic overview of the measurement properties of functional walk tests used in the cardiorespiratory domain. Chest. 2001;119:256-270.

[18] Parreira VF, Janaudis-Ferreira T, Evans RA, et al. Measurement properties of the incremental shuttle walk test, a systematic review. Chest. 2014;145:1357-1369.
[19] Probst VS, Hernandes NA, Teixeira DC, et al. Reference values for the incremental shuttle walking test. Respir Med. 2012;106:243-248.

[20] Harrison SL, Greening NJ, Houchen-Wolloff L, et al. Agespecific normal values for the incremental shuttle walk test in a healthy British population. J Cardiopulm Rehabil Prev. 2013;33:309-313.

[21] Erdmann PG, Teunissen LL, van Genderen FR, et al. Functioning of patients with chronic idiopathic axonal polyneuropathy (CIAP). J Neurol. 2007;254:1204-1211.

[22] Erdmann PG, Lindeman E, Cats EA, et al. Functioning of patients with multifocal motor neuropathy. J Peripher Nerv Syst. 2010;15:113-119.

[23] Notermans NC, Wokke JHJ, Franssen $\mathrm{H}$, et al. Chronic idiopathic polyneuropathy presenting in middle or old age: a clinical and electrophysiological study of 75 patients. J Neurol Neurosurg Psychiatry. 1993;56:1066-1071.

[24] van Asseldonk JT, Franssen $H$, van den Berg-Vos RM, et al. Multifocal motor neuropathy. Lancet Neurol. 2005;4:309-319.

[25] van Swieten JC, Koudstaal PJ, Visser MC, et al. Interobserver agreement for the assessment of handicap in stroke patients. Stroke. 1988;19:604-607.

[26] Hulzebos EHJ, van Elk N, Sabelis LWE, et al. De validiteit van de gemodificeerde shuttle Wandel test bij patiënten met chronisch hartfalen. Ned Tijdschr Fysiother. 2006;116:16-20.

[27] Borg GA. Psychophysical bases of perceived exertion. Med Sci Sports Exerc. 1982;14:377-381.

[28] Pestman WR. Mathematical Statistics: an introduction. Berlin: Walter de Gruyter Verlag; 1998.

[29] Brach JS, VanSwearingen JM, Newman AB, et al. Identifying early decline of physical function in community-dwelling older women: performance-based and self-report measures. Phys Ther. 2002;82:320-328.

[30] Novak P, Burger $H$, Marincek $C$, et al. Influence of foot pain on walking ability of diabetic patients. J Rehabil Med. 2004;36:249-252.

[31] Mathur S, Reid WD, Levy RD. Exercise limitation in recipients of lung transplants. Phys Ther. 2004;84:1178-1187.

[32] Tanaka H, Monahan KD, Seals DR. Age-predicted maximal heart rate revisited. J Am Coll Cardiol. 2001;37:153-156.

[33] Stratford PW, Binkley FM, Riddle DL. Health status measures: strategies and analytic methods for assessing change scores. Phys Ther. 1996;76:1109-1123.

[34] Glasziou P, Irwig L, Mant D. Monitoring in chronic disease: a rational approach. BMJ. 2005;330:644-648.

[35] van Nes SI, Faber CG, Merkies IS. Outcome measures in immune-mediated neuropathies: the need to standardize their use and to understand the clinimetric essentials. J Peripher Nerv Syst. 2008;13:136-147. 


\section{Appendix}

Neuropathy shuttle walk test

Name:

Date:

Walking aid:

No. of Shuttles:

Patient stopped test/patient did not reach cone in time/patient walked all 150 shuttles*

Reason test termination:

\begin{tabular}{|c|c|c|c|c|c|c|c|c|}
\hline Speed & Time & Score & Speed & Time & Score & Speed & Time & Score \\
\hline $3 \mathrm{~km} / \mathrm{h}$ & 00:00:00 & 0 & $5 \mathrm{~km} / \mathrm{h}$ & 00:08:05 & 51 & $6.5 \mathrm{~km} / \mathrm{h}$ & $00: 13: 58$ & 105 \\
\hline \multirow[t]{9}{*}{ (LEVEL 1) } & $0: 00: 12$ & 1 & (LEVEL 5) & 00:08:12 & 52 & (LEVEL 8) & 00:14:03 & 106 \\
\hline & $0: 00: 24$ & 2 & & 00:08:19 & 53 & & 00:14:09 & 107 \\
\hline & 0:00:36 & 3 & & 00:08:27 & 54 & & 00:14:14 & 108 \\
\hline & 0:00:48 & 4 & & 00:08:34 & 55 & & $00: 14: 20$ & 109 \\
\hline & 0:01:00 & 5 & & 00:08:41 & 56 & & $00: 14: 25$ & 110 \\
\hline & 0:01:12 & 6 & & 00:08:48 & 57 & & 00:14:31 & 111 \\
\hline & $0: 01: 24$ & 7 & & 00:08:55 & 58 & & $00: 14: 36$ & 112 \\
\hline & 0:01:36 & 8 & & 00:09:03 & 59 & & 00:14:42 & 113 \\
\hline & 0:01:48 & 9 & & 00:09:11 & 60 & & 00:14:47 & 114 \\
\hline $3.5 \mathrm{~km} / \mathrm{h}$ & 0:02:00 & 10 & & 00:09:18 & 61 & & 00:14:53 & 115 \\
\hline \multirow{11}{*}{ (LEVEL 2) } & 0:02:10 & 11 & & 00:09:25 & 62 & & 00:14:58 & 116 \\
\hline & $0: 02: 20$ & 12 & & 00:09:32 & 63 & & 00:15:04 & 117 \\
\hline & 0:02:30 & 13 & & 00:09:40 & 64 & & 00:15:09 & 118 \\
\hline & $0: 02: 40$ & 14 & & 00:09:47 & 65 & & 00:15:15 & 119 \\
\hline & 0:02:50 & 15 & & 00:09:54 & 66 & & 00:15:20 & 120 \\
\hline & 0:03:00 & 16 & $5.5 \mathrm{~km} / \mathrm{h}$ & 00:10:01 & 67 & & $00: 15: 26$ & 121 \\
\hline & 0:03:10 & 17 & (LEVEL 6) & 00:10:07 & 68 & & 00:15:31 & 122 \\
\hline & 0:03:20 & 18 & & 00:10:14 & 69 & & 00:15:37 & 123 \\
\hline & 0:03:30 & 19 & & 00:10:20 & 70 & & 00:15:42 & 124 \\
\hline & 0:03:40 & 20 & & 00:10:27 & 71 & & 00:15:48 & 125 \\
\hline & 0:03:50 & 21 & & $00: 10: 33$ & 72 & & 00:15:53 & 126 \\
\hline $4 \mathrm{~km} / \mathrm{h}$ & 0:04:00 & 22 & & 00:10:40 & 73 & $7 \mathrm{~km} / \mathrm{h}$ & 00:15:59 & 127 \\
\hline \multirow[t]{13}{*}{ (LEVEL 3) } & 00:04:09 & 23 & & $00: 10: 46$ & 74 & (LEVEL 9) & 00:16:04 & 128 \\
\hline & 00:04:17 & 24 & & $00: 10: 53$ & 75 & & 00:16:09 & 129 \\
\hline & 00:04:26 & 25 & & 00:11:00 & 76 & & 00:16:14 & 130 \\
\hline & 00:04:35 & 26 & & 00:11:06 & 77 & & $00: 16: 20$ & 131 \\
\hline & 00:04:44 & 27 & & 00:11:12 & 78 & & $00: 16: 25$ & 132 \\
\hline & 00:04:53 & 28 & & 00:11:19 & 79 & & 00:16:30 & 133 \\
\hline & 00:05:02 & 29 & & $00: 11: 25$ & 80 & & 00:16:35 & 134 \\
\hline & 00:05:11 & 30 & & 00:11:32 & 81 & & 00:16:40 & 135 \\
\hline & 00:05:20 & 31 & & 00:11:38 & 82 & & $00: 16: 45$ & 136 \\
\hline & 00:05:29 & 32 & & 00:11:45 & 83 & & 00:16:50 & 137 \\
\hline & 00:05:38 & 33 & & $00: 11: 51$ & 84 & & 00:16:56 & 138 \\
\hline & 00:05:47 & 34 & $6 \mathrm{~km} / \mathrm{h}$ & 00:11:58 & 85 & & 00:17:01 & 139 \\
\hline & 00:05:56 & 35 & (LEVEL 7) & 00:12:04 & 86 & & 00:17:06 & 140 \\
\hline $4.5 \mathrm{~km} / \mathrm{h}$ & 00:06:05 & 36 & & $00: 12: 10$ & 87 & & 00:17:11 & 141 \\
\hline \multirow{17}{*}{ (LEVEL 4) } & 00:06:13 & 37 & & 00:12:16 & 88 & & $00: 17: 16$ & 142 \\
\hline & 00:06:21 & 38 & & $00: 12: 22$ & 89 & & $00: 17: 22$ & 143 \\
\hline & 00:06:29 & 39 & & $00: 12: 28$ & 90 & & $00: 17: 27$ & 144 \\
\hline & 00:06:37 & 40 & & $00: 12: 34$ & 91 & & $00: 17: 32$ & 145 \\
\hline & 00:06:45 & 41 & & 00:12:40 & 92 & & 00:17:38 & 146 \\
\hline & 00:06:53 & 42 & & $00: 12: 46$ & 93 & & $00: 17: 43$ & 147 \\
\hline & 00:07:01 & 43 & & $00: 12: 52$ & 94 & & 00:17:48 & 148 \\
\hline & 00:07:09 & 44 & & 00:12:58 & 95 & & 00:17:53 & 149 \\
\hline & 00:07:17 & 45 & & 00:13:04 & 96 & & 00:17:59 & 150 \\
\hline & 00:07:25 & 46 & & 00:13:10 & 97 & & & \\
\hline & 00:07:33 & 47 & & 00:13:16 & 98 & & & \\
\hline & 00:07:41 & 48 & & 00:13:22 & 99 & & & \\
\hline & 00:07:49 & 49 & & $00: 13: 28$ & 100 & & & \\
\hline & 00:07:57 & 50 & & 00:13:34 & 101 & & & \\
\hline & & & & 00:13:40 & 102 & & & \\
\hline & & & & 00:13:46 & 103 & & & \\
\hline & & & & 00:13:52 & 104 & & & \\
\hline
\end{tabular}

